\title{
Erratum
}

\section{Reaction of a Polycyclic Diketone with Lithiated Methoxyallene: Synthesis of New Functionalized Cage Compounds}

Reinhold Zimmer, Maurice Taszarek, Luise Schefzig, Hans-Ulrich Reissig* Synlett 2008, 2046.

In the printed version of this manuscript, the last paragraph of page 2046 was repeated as the first of page 2047. Instead, Equation 1 should have appeared:

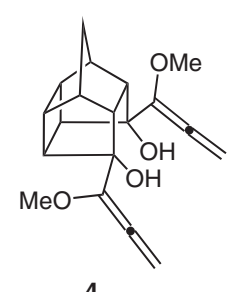

4

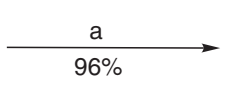

Equation 1 Dehydration of 4. Reagents and conditions: a) $\mathrm{MsCl}, \mathrm{Et}_{3} \mathrm{~N}, \mathrm{CH}_{2} \mathrm{Cl}_{2}, 0{ }^{\circ} \mathrm{C}, 30$ min; r.t., 2.5 h.

The electronic version of this manuscript remains complete. 